\title{
MARCINKIEWICZ INTEGRALS ASSOCIATED WITH SCHRÖDINGER OPERATOR ON GENERALIZED MORREY SPACES
}

\author{
Ali Akbulut and OKan KuZu
}

Abstract. Let $L=-\Delta+V$ be a Schrödinger operator, where $\Delta$ is the Laplacian on $\mathbb{R}^{n}$, while nonnegative potential $V$ belongs to the reverse Hölder class. In this paper, we study the boundedness of the Marcinkiewicz operator associated with Schrödinger operator $\mu_{j}^{L}$ on generalized Morrey spaces $M_{p, \varphi}$. We find the sufficient conditions on the pair $\left(\varphi_{1}, \varphi_{2}\right)$ which ensures the boundedness of the operators $\mu_{j}^{L}$ from one generalized Morrey space $M_{p, \varphi_{1}}$ to another $M_{p, \varphi_{2}}$, $1<p<\infty$ and from the space $M_{1, \varphi_{1}}$ to the weak space $W M_{1, \varphi_{2}}$.

Mathematics subject classification (2010): 42B20, 42B35.

Keywords and phrases: Marcinkiewicz operator, Schrödinger operator, generalized Morrey space.

\section{REFERENCES}

[1] A. Akbulut, V. S. Guliyev and R. Mustafayev, On the boundedness of the maximal operator and singular integral operators in generalized Morrey spaces, Math. Bohem. 137 (1) (2012), 27-43.

[2] A. Al-Salman, H. Al-Qassem, L. C. Cheng, Y. Pan, $L_{p}$ bounds for the function of Marcinkiewicz, Math. Res. Lett. 9 (2002) 697-700.

[3] A. Benedek, A. P. Calderon, R. Panzone, Convolution operators on Banach value functions, Proc. Natl. Acad. Sci. USA 48 (1962), 256-265.

[4] V. I. Burenkov, A. Gogatishvili, V. S. Guliyev, R. Ch. Mustafayev, Boundedness of the Riesz potential in local Morrey-type spaces, Potential Analysis, 35 (2011), no. 1, 67-87.

[5] G. Di FAZIO, M. A. RAGUSA, Interior estimates in Morrey spaces for strong solutions to nondivergence form equations with discontinuous coefficients, J. Funct. Anal. 112 (1993) 241-256.

[6] D. FAN, S. LU AND D. YANG, Boundedness of operators in Morrey spaces on homogeneous spaces and its applications, Acta Math. Sinica (N. S.) 14 (1998), suppl., 625-634.

[7] Y. DiNG, D. YANG, Z. ZHOU, Boundedness of sublinear operators and commutators on $L^{p, \omega}\left(\mathbb{R}^{n}\right)$, Yokohama Mathematical, 46 (1998), 15-27.

[8] J. DZIUbańs Ki, J. Zienkiewicz, Hardy space $H^{1}$ associated to Schrödinger operator with potential satisfying reverse Hölder inequality, Rev. Mat. Iber. 15 (1999), 279-296.

[9] Y. Ding, On Marcinkiewicz integral, in: Proc. of the Conference "Singular Integrals and Related Topics, III", Osaka, Japan, 2001, pp. 28-38.

[10] W. GAO, L. TANG, Boundedness for Marcinkiewicz integrals associated with Schrdinger operators, Indian Academy of Sci., 2012. (to appear).

[11] M. GIAQUintA, Multiple integrals in the calculus of variations and nonlinear elliptic systems, Princeton Univ. Press, Princeton, NJ, 1983.

[12] V. S. GULIYEV, Integral operators on function spaces on the homogeneous groups and on domains in $\mathbb{R}^{n}$, Doctoral dissertation, Moscow, Mat. Inst. Steklov, 1994, 329 pp. (in Russian).

[13] V. S. GuliYEV, Function spaces, integral operators and two weighted inequalities on homogeneous groups. Some applications, Baku, Elm. 1999, 332 pp. (Russian).

[14] V. S. GuliYeV, Boundedness of the maximal, potential and singular operators in the generalized Morrey spaces, J. Inequal. Appl. 2009, Art. ID 503948, 20 pp.

[15] V. S. Guliyev, S. S. Aliyev, T. Karaman, Boundedness of a class of sublinear operators and their commutators on generalized Morrey spaces, Abstr. Appl. Anal. vol. 2011, Art. ID 356041, 18 pp. doi:10.1155/2011/356041. 
[16] V. S. Guliyev, Seymur S. Aliyev, Boundedness of parametric Marcinkiewicz integral operator and their commutators on generalized Morrey spaces, Georgian Math. J. 19 (2012), 195-208.

[17] L. Hörmander, Translation Invariant Operators, Acta Math., 104 (1960), 93-139.

[18] A. Kufner, O. John And S. FučIK, Function Spaces, Noordhoff International Publishing: Leyden, Publishing House Czechoslovak Academy of Sciences: Prague, 1977.

[19] G. LU, S. LU, D. YANG, Singular integrals and commutators on homogeneous groups, Analysis Mathematica, 28 (2002) 103-134.

[20] C. B. Morrey, On the solutions of quasi-linear elliptic partial differential equations, Trans. Amer. Math. Soc. 43 (1938), 126-166.

[21] Z. SHEN, $L^{p}$ estimates for Schrödinger operators with certain potentials, Ann. Inst. Fourier (Grenoble) 45 (1995) 513-546.

[22] F. SORIA, G. WeISS, A remark on singular integrals and power weights, Indiana Univ. Math. J. 43 (1994) 187-204.

[23] E. M. Stein, On the functions of Littlewood-Paley, Lusin, and Marcinkiewicz, Trans. Amer. Math. Soc. 88 (1958), 430-466.

[24] T. Walsh, On the function of Marcinkiewicz, Studia Math. 44 (1972) 203-217. 